\title{
Articulando ações com o GESTAR
}

DOI: 10.23864/cpp-v1-n1-68

Adriana Cruz de Souza

\section{Resumo}

Apresentamos aqui um relato das atividades desenvolvidas com o programa "GESTAR na Escola", no Colégio Estadual Camilo de Jesus Lima, localizado no município de Vitória da Conquista-Bahia, pelos professores de Matemática das séries finais do ensino fundamental II, no decorrer do ano de 2014. Através de técnicas e materiais adequados foram desenvolvidas atividades para explorar o que há de mais divertido, prático e criativo na Matemática, como forma de envolver os alunos na busca do novo conhecimento. Neste sentido, o programa de Gestão da Aprendizagem Escolar, mais conhecido como "GESTAR", revelou-se de grande importância para o desenvolvimento de estratégias eficazes para o ensino-aprendizagem, uma vez que permitiu aos alunos o domínio de conteúdos básicos de forma prática e contextualizada, tornando a aprendizagem mais significativa. As atividades elaboradas pelo GESTAR aqui relatadas, foram construídas juntamente com os professores e aplicadas nas turmas conforme o grau de compreensão de cada série escolar. Esse material fez parte dos projetos pedagógicos da escola, utilizando a contextualização e a interdisciplinaridade como forma de integrar os alunos e ao mesmo tempo formalizar conceitos. Assim, os conhecimentos prévios dos alunos interagiram com as novas informações e um novo conhecimento foi formado, deixando de lado a educação baseada na formação de modelos, memorizações e fragmentações. Dessa forma, os resultados obtidos foram notados no dia-a-dia dos alunos, que passaram a dar sentido a simples atividades escolares

Palavras-chave: Conhecimento. Contextualização.

Interdisciplinaridade. 


\section{Introdução}

As informações veiculadas no mundo que nos cerca, ora profissional ora pessoal, necessitam do conhecimento matemático como ferramenta essencial para a leitura e interpretação, pois a Matemática está presente em todas as áreas do conhecimento. No ensino da Matemática é necessário desenvolver a capacidade de expressão e de raciocínio e, portanto, nessa perspectiva espera-se que sua construção ocorra de forma integrada, contextualizada e significativa, possibilitando ao aluno a associação daquilo que aprende a outros campos do conhecimento e ao cotidiano.

Temos observado que pouco tem sido feito relativo aos estudos da Matemática em sala de aula, embora tenhamos vários trabalhos acadêmicos com esse enfoque, observamos que dentro das escolas continuamos a repetir os mesmos erros de nossos antecessores. A falta de significado dos conteúdos apresentados tem origem nas primeiras séries e vai se agravando nas séries subsequentes.

Muitas vezes os conceitos, propriedades e relações necessárias à aprendizagem dos conteúdos são trazidas prontas pelos professores para dentro da sala de aula e sem veiculação com os objetos que os cercam, o que distancia a Matemática da realidade, causando frustração, desmotivação e dificuldades ao alunado. Os estudantes não são instigados a construir, comparar, conjecturar, abstrair, concluir e por fim generalizar os conceitos, portanto, não superam dificuldades, não aprendem.

Dessa forma, podemos perceber que muitas são as dificuldades encontradas por alunos e professores no processo ensino-aprendizagem da Matemática. Por um lado, os alunos se desmotivam quando não conseguem estabelecer relações entre o conteúdo ensinado pelo professor e sua aplicabilidade na vida e, por outro lado, o professor que não consegue alcançar resultados satisfatórios junto a seus alunos, uma vez que, não consegue envolvê-los em suas aulas.

No seu resgate histórico, observamos o advento do Movimento Internacional da Matemática Moderna, no início da década de 6o, que consubstanciou vários grupos de estudo e fez emergir vários trabalhos, encontros, artigos e projetos dedicados a Educação Matemática e que apesar dos aportes teóricos, o cenário não se alterou muito e de maneira mais particular, em relação à Geometria, que avançou pouco. Mesmo com as práticas voltadas para a resolução de problemas e modelagem matemática, ainda estamos perdidos segundo pesquisas realizadas nas últimas décadas.

A formação de professores tem sido pauta frequente de inúmeras discussões no âmbito acadêmico. Com o objetivo de melhorar o processo de ensino-aprendizagem, o Ministério da Educação disponibilizou aos Municípios e Estados o programa Gestão da Aprendizagem 
Escolar (GESTAR), permitindo ao professor o desenvolvimento de um trabalho baseado em habilidades e competências.

A aplicação de situações-problema contextualizadas, além de despertar a curiosidade dos alunos, é uma forma de envolvê-los na compreensão e resolução da atividade. Assim através de situações investigativas e de exploração, com a finalidade de relacionar os fenômenos estudados, é possível tornar a aprendizagem mais significativa, pois o uso de linguagens diferenciadas facilitará a articulação de seus conhecimentos.

\section{O GESTAR}

O Programa Gestão da Aprendizagem Escolar (GESTAR), é um projeto implementado pelo governo do Estado da Bahia com base nos Parâmetros Curriculares Nacionais (PCN) e que tem por ação o fortalecimento do ensino público. O GESTAR foi desenvolvido como ferramenta de preparação de professores em nível de formação continuada semipresencial nas áreas de Língua Portuguesa e Matemática. Era intitulado de GESTAR II e o formador, especialista do programa, coordenava todas as atividades propostas e aplicadas na escola, pois era na sala de aula que o GESTAR se efetivava.

O material didático do GESTAR está organizado em três eixos curriculares: Conhecimentos Matemáticos, Conhecimentos de Educação Matemática e Transposição Didática. A partir das situações-problema exploradas, esses três elementos são construídos e um novo meio de aprender Matemática é vivenciado.

No eixo Conhecimentos Matemáticos, o professor através de situações-problema do cotidiano dos alunos, mobiliza conhecimentos Matemáticos prévios permitindo ao aluno explorar, identificar, conjecturar e descobrir um novo conhecimento. O segundo eixo estruturante consiste nos Conhecimentos de Educação Matemática, onde o professor se apropria de uma nova maneira de aprender Matemática com problemas situacionais que compõem o mundo real. E por fim, o eixo Transposição Didática, com a ideia de trabalhar os conteúdos em sala de aula de forma que os alunos passam a compreendê-los melhor.

Desde 2011, o programa vem atuando com uma nova formatação intitulada "GESTAR na Escola” e atende às disciplinas de Português e Matemática do $6^{\circ}$ ao $9^{\circ}$ ano através de um trabalho colaborativo e articulado. O projeto-ação "GESTAR na Escola” mobiliza um trabalho docente articulado por grupos constituídos de professores em serviço, assistidos por formadores do Programa GESTAR-Bahia.

As ações pedagógicas desenvolvidas com o GESTAR proporcionam aos alunos uma percepção de como a Matemática está presente em nosso dia-a-dia e como é de fundamental importância a habilidade de interpretar e resolver problemas. 
Durante o processo de aprendizagem, o aluno é estimulado a conhecer, pesquisar e produzir. Assim, partindo de uma situação real irá buscar a solução através da construção do conhecimento matemático. Dessa forma, é possível desenvolver no aluno a capacidade de pensar e criar suas próprias estratégias de resolução, formalizando os conceitos e tornando a aprendizagem mais significativa.

A proposta pedagógica desenvolvida pelo GESTAR entra em ação pela transposição didática e os conteúdos matemáticos são trabalhados de forma contextualizada. Philipe Perrenoud conceitua "transposição didática" como "a ação de fabricar artesanalmente os saberes, tornando-os ensináveis, exercitáveis e passíveis de avaliação no quadro de uma turma, de um ano, de um horário, de um sistema de comunicação e trabalho” (PERRENOUD, 1993, p.25). Assim, partindo de uma situação-problema da realidade sócio-cultural, alunos e professores constroem o conhecimento em sala de aula por meio de atividades ora individuais, ora coletivas.

\section{A nossa escola}

O Colégio Estadual Camilo de Jesus Lima está localizado no bairro Patagônia em Vitória da Conquista-Bahia. A unidade escolar tem capacidade para atender aproximadamente 1000 estudantes e conta com estrutura física completa, que compreende oito salas de aula, quadra esportiva, sala de vídeo, informática e biblioteca.

O Colégio começou as atividades no ano letivo de 2013, e conta, atualmente, com 728 estudantes matriculados nos três turnos, com ensino fundamental no vespertino e médio no matutino e noturno. A maioria dos alunos é oriunda de família de baixa renda e dependem dos programas sociais do governo federal para viverem.

O Ensino de Matemática no Colégio Camilo de Jesus Lima segue os Parâmetros Curriculares Nacionais, sendo assim estruturado nos seguintes eixos estruturantes (a) números e operações, (b) espaço e forma, (c) grandezas e medidas e (d) tratamento da informação. Nesse sentido, o desenvolvimento dos conteúdos ocorre de tal forma que, ao se passar dos anos, os estudantes terão condições de ampliar e aprofundar os significados dos conceitos e relacionar cada novo conceito a outros, matemáticos ou de outras áreas do conhecimento.

\section{Atividades desenvolvidas com o gestar}

Durante o ano de 2014, o Colégio Camilo de Jesus Lima desenvolveu alguns projetos pedagógicos e a proposta do GESTAR esteve inserida em todos eles, como forma de introduzir 
uma nova maneira de fazer do professor, contribuindo de forma significativa na aprendizagem dos alunos. Segundo Paulo Freire, no trabalho com projetos:

Tanto educadores quanto educandos envoltos numa pesquisa, não serão mais os mesmos. Os resultados devem implicar em mais qualidade de vida, devem ser indicativos de mais cidadania, de mais participação nas decisões da vida cotidiana e da vida social. Devem, enfim, alimentar o sonho possível e a utopia necessária para uma nova lógica de vida (FREIRE, 1994, p.36)

Dessa forma, procurando sempre colocar os alunos como protagonistas, realizamos um trabalho interdisciplinar de ensino-aprendizagem buscando resultados significativos, fazendo sempre a ponte entre o que se vive e o que se aprende na escola, não deixando de formalizar os conteúdos e também de construir uma sociedade pensante. Assim, através da contextualização, o conhecimento passa a ter maior significado para o aluno, pois requer a intervenção do estudante em todo o processo de aprendizagem.

A proposta de se trabalhar com projetos envolve uma série de ações que devem ser planejadas para que ocorra o total envolvimento de todos, alunos e professores. A interdisciplinaridade tem que caminhar de forma estruturada para que ocorram as interações entre as disciplinas. $\mathrm{O}$ espaço escolar tem que se tornar aberto, receptivo, para que os alunos tenham oportunidade de expressar suas ações, desenvolvendo um maior contato consigo próprios, com os outros e com o mundo que os rodeia. Dessa forma é possível obter resultados satisfatórios.

\section{Projeto Brasil em foco}

O projeto "Brasil em Foco" foi um projeto de aprendizagem interdisciplinar que teve como temática a Copa do Mundo de Futebol 2014, no Brasil. Criando situações de ensino e aprendizagem, aproveitando o momento de mobilização e motivação vivenciado pela sociedade brasileira, os conteúdos das áreas de conhecimento foram trabalhados de forma desafiadora e criativa, estimulando a relação entre a vida e a escola.

As atividades desenvolvidas na área de Matemática com o GESTAR, foram aplicadas em três sequências didáticas, com objetivo de incentivar a produção de conhecimento através de transposições didáticas. Todas as atividades foram planejadas com base nas habilidades e competências propostas nos Parâmetros Curriculares Nacionais. Para Antoni Zabala,

Sequências didáticas são um conjunto de atividades ordenadas, estruturadas e articuladas para a realização de certos objetivos educacionais, que têm um princípio e um fim conhecidos tanto pelos professores como pelos alunos, que têm a virtude de manter o caráter unitário e reunir toda a complexidade da prática (ZABALA, 1998, p.18) 
Portanto, nosso desafio foi fazer com que os alunos compreendessem a linguagem matemática e suas representações, através da exploração e investigação de situaçõesproblema, tornando possível aos estudantes tomarem consciência de conceitos matemáticos, que os auxiliem na construção de uma visão crítica do mundo.

A primeira sequência didática teve como tema "A Copa em Números", e através da construção de tabelas, os alunos puderam estabelecer relações entre dados que pesquisaram e também representar o máximo de informações num mínimo espaço, afinal, as tabelas são estruturas que resumem um conjunto de observações.

Iniciamos a atividade motivando os alunos com vídeos sobre a Copa do Mundo de futebol, onde contava a história e curiosidades das copas, a participação do Brasil, os "mascotes", o uso da tecnologia, a escolha do Brasil para a copa 2014, estimulando assim a curiosidade deles.

Com o objetivo de explorar a construção de tabelas e ao mesmo tempo discutir os fatos importantes relacionados à Copa do Mundo 2014, foi solicitada aos alunos uma pesquisa sobre o maior campeonato mundial de futebol, como: os países campeões de todos os tempos, cidades-sede da copa, os gastos com os estádios, capacidade de público de cada estádio, etc, e posteriormente essas informações foram organizadas e apresentadas na forma de tabelas, para registrar a pesquisa.

Cada turma pesquisou um dado diferente obedecendo ao nível de compreensão de cada série escolar, de forma a garantir que todos desenvolvessem a atividade proposta. No decorrer do processo vários conteúdos matemáticos foram abordados e pudemos perceber que quando o envolvimento dos estudantes é efetivo o resultado é apresentado com sucesso.

Muitos questionamentos sobre a Copa do Mundo no Brasil foram feitos, muitas informações foram compartilhadas e uma nova aquisição da linguagem matemática foi aprendida, pois os alunos passaram a estabelecer relações comparativas através da análise de tabelas, que foi em seguida apresentada no espaço escolar para troca de experiências entre as classes, visto que a socialização faz parte do processo de aprendizagem.

Nesta perspectiva, o GESTAR funcionou como ponte na construção do conhecimento, onde o professor se tornou um mediador, levando o aluno a refletir sobre o seu trabalho e ajudando a chegar ao objetivo proposto. De acordo com Tomazzeti:

O professor, na perspectiva da interdisciplinaridade, não é um mero repassador de conhecimentos, mas é reconstrutor juntamente com seus alunos; o professor é, conseqüentemente, um pesquisador que possibilita aos alunos, também, a prática da pesquisa (TOMAZZETI, 1998, p.13).

Dessa forma, promovendo a interdisciplinaridade na escola, foi possível que os professores incentivassem os alunos a construírem relações entre os diferentes conteúdos presentes nas diversas disciplinas do currículo. 
Na Matemática, os alunos perceberam que quando as informações presentes em uma tabela são lidas, há uma riqueza de informações que são apresentadas de forma objetiva e clara. E, para chegar a essa conclusão, os professores relacionaram a fala do aluno com o tema abordado, mediando estratégias para ressignificar o seu modo de ver, despertando a busca pelo conhecimento, capacitando-os a superar as dificuldades apresentadas inicialmente em organizar as ideias e apresentá-las de forma clara.

O trabalho com tabelas contribuiu para a aprendizagem dos eixos estruturantes dos PCN "números e operações" e "tratamento da informação", levando em conta os diferentes estágios de desenvolvimento dos alunos. Percebemos que os alunos das séries finais tiveram um pouco mais de dificuldade devido ao nível de abstração solicitado na atividade. Aparentemente, tiveram um bom desempenho.

A segunda sequência didática teve como tema "A Construção da Bola" e, como o GESTAR provoca nos alunos o princípio investigativo, vários conteúdos de Geometria foram explorados e conceitos foram formalizados. O eixo estruturante dos PCN abordado nessa transposição didática foi “espaço e forma”, fazendo com que a geometria ganhasse mais espaço em sala de aula, não só para desenvolver a criatividade, mas também no uso do raciocínio ao trabalhar com figuras, muitas vezes, abstratas.

A história do ensino da Matemática no Brasil, e, por conseguinte, da Geometria, foi marcada pelo mecanicismo, com memorização de regras, sem conexão com situações presentes, tornando o ensino e o trabalho com a mesma um "vago específico", sem clareza, omisso, inadequado e totalmente desinteressante. Segundo Lorenzato:

A Geometria está por toda parte..., mas é preciso conseguir enxerga-lá..., mesmo não querendo, se lida no cotidiano com as ideias de paralelismo, perpendicularismo, semelhança, proporcionalidade, medição (comprimento, área, volume), simetria: seja pelo visual (formas), seja pelo uso no lazer, na profissão, na comunicação oral, cotidianamente se está envolvido com a Geometria (LORENZATO, 1995, p.5).

Assim sendo, o trabalho com figuras espaciais deve despertar a curiosidade, desenvolver a percepção espacial e ser efetivamente significativa, deve ser um desafio prazeroso para quem aprende e quem ensina. Portanto, o aluno deve manipular figuras, construir sólidos e para tanto realizamos uma sequência didática envolvendo a construção da bola de futebol, na qual, foram trabalhadas as figuras bidimensionais e tridimensionais, que muitas vezes gera um pouco de confusão no processo de transformação.

Para encaminhamento metodológico na execução dessa atividade, nos apropriamos de um princípio do National Council of Teachers of Mathematics - NCTM - (Apud NACARATO, 2003, p 95) para justificar essa ideia: 
A compreensão espacial é necessária para interpretar, compreender e apreciar o nosso mundo, que é intrinsecamente geométrico. As idéias e as intuições acerca das formas bi e tridimensionais e das suas características, as interrelações entre as formas e os efeitos das modificações nas formas, são aspectos importantes do sentido espacial. Para aprender geometria, as crianças precisam de investigar, experimentar e explorar, usando tanto os objetos do quotidiano como outros materiais físicos específicos. (NCTM, 1991, p.60)

No decorrer do processo, os alunos foram motivados com curiosidades a respeito das bolas das Copas do Mundo de futebol como: a evolução da bola de futebol, como diferentes materiais foram sendo testados para sua fabricação, tudo para que não sofresse alteração de peso, medida e formato durante a partida. Foi solicitada para cada série uma construção diferente da bola de futebol, mudando apenas o enfoque dado ao conteúdo, levando os alunos a refletirem sobre as possibilidades e dificuldades enfrentadas para a realização da mesma.

A construção da bola tem por trás uma complexa formação de figuras geométricas. É uma multíplice rede constituída por hexágonos e pentágonos unidos pelas arestas, e todo este emaranhado de polígonos e ângulos que se unem a um objeto simetricamente perfeito é denominado de "bola de futebol".

Durante a atividade de construção da bola percebemos que a manipulação de materiais gerou uma inquietação por parte dos alunos e dificuldades, principalmente em cortar, montar e interagir com seus pares, pois eles queriam fazer cada um uma coisa ao mesmo tempo.

Apesar das dificuldades encontradas, o conhecimento geométrico foi trabalhado sob a perspectiva da transposição didática que criou um espaço propício à criação e manipulação desses materiais, pois os alunos tiveram oportunidade de resolver problemas e sistematizar as informações obtidas, passando para a fase de abstração sem ter queimado etapas.

A terceira e última sequência didática teve como tema "Entram no Campo as Relações Geométricas”, proporcionando que conteúdos Matemáticos e Geométricos fossem explorados, com o intuito de ressiginificar os conceitos.

A falta de significado dos conteúdos apresentados tem origem nas primeiras séries e vai se agravando nas séries subsequentes. Vários estudos são realizados no intuito de encontrar uma solução. Segundo Pavanello, normalmente, ao ensinar Geometria, o professor não se preocupa "em trabalhar as relações existentes entre as figuras, fato esse que não auxilia o aluno a progredir para um nível superior de compreensão de conceitos” (PAVANELLO, 2001, p.183).

Assim, com essa atividade, os alunos puderam explorar as linhas que delimitam o campo e determinam a marcação de faltas, os ângulos do campo e a área no gramado para cada membro do time atacar ou defender, comprovando que os conhecimentos geométricos são estruturantes para um jogo, tornando a aprendizagem mais significativa e não apenas mera memorização.

Os conteúdos trabalhados nesta atividade foram: as formas geométricas, posições entre retas, simetria, escala e ângulos. Os eixos estruturantes dos PCN vivenciados foram "números 
e operações", "grandezas e medidas" e "espaço e forma", onde pudemos trazer vivências do cotidiano e adaptá-las aos conteúdos escolares, já que o campo de futebol faz parte da vida de muitos deles.

O Projeto "Brasil em Foco" teve formato baseado na Copa do Mundo de futebol, tendo nas atividades pedagógicas as "partidas", na avaliação das ações o "gol”, no trabalho em grupo as "seleções", nos espaços escolares os "estádios". As ações propostas foram desenvolvidas e registradas em portfólios por todos os professores nas suas devidas áreas de conhecimento.

\section{Projeto Ambientando}

O projeto "Ambientando" foi também um projeto de aprendizagem interdisciplinar desenvolvido no ano de 2014 cujas etapas foram desenvolvidas no segundo semestre letivo e teve como objetivo gerar novos conceitos sobre a importância da preservação do meio ambiente no dia-a-dia. O projeto desenvolvido na escola abordou questões relativas ao nosso planeta com a intenção de conscientizar os nossos alunos sobre a importância de preservar o meio ambiente saudável e incorporar valores individuais e sociais na prática para não comprometer o ambiente em que vivemos.

Durante o processo cada disciplina trabalhou com um tema gerador, interligando as diversas áreas de conhecimento a um único objetivo, conscientizar os estudantes na preservação do meio ambiente tendo como culminância a criação da horta escolar.

As atividades desenvolvidas com o GESTAR foram aplicadas em diversos momentos e teve como tema gerador a "Compostagem”. Com a finalidade de associar o uso da Matemática ao tema e estabelecer uma série de transposições didáticas que viabilizasse a exploração e a investigação, foram criadas situações de aprendizagem com conteúdos e objetos matemáticos, levando o aluno a perceber que a Matemática faz parte do nosso dia-a-dia e não apenas da sala de aula.

Tendo como foco as finalidades do ensino da Matemática, os PCN apontam como objetivos do Ensino Fundamental conduzir o aluno a:

Identificar os conhecimentos matemáticos como meios para compreender e transformar o mundo à sua volta e perceber o caráter de jogo intelectual, característico da Matemática, como aspecto que estimula o interesse, a curiosidade, o espírito de investigação e o desenvolvimento da capacidade para resolver problemas. (BRASIL, 1997, p.37)

Assim, percebemos que os motivando no sentido da aquisição de uma aprendizagem investigativa conseguimos estimular os alunos a fazer e explicar a Matemática relacionando-a a vários conteúdos. 
Na primeira etapa do projeto, exibimos o filme Wall-E: "os impactos causados pelo lixo e a necessidade de reciclar", como forma de sensibilizar os alunos para os problemas que estamos enfrentando com a falta de cuidado com o meio ambiente. Em seguida, como forma de mobiliza-los para mudança de atitude, foi confeccionado um mural com a seguinte pergunta: "Baseado no filme Wall-E, como impedir que algo parecido aconteça com o nosso planeta?", onde foram deixados os relatos elaborados por eles.

O filme Wall-E entrou no projeto como componente articulador e interdisciplinar buscando não apenas o entretenimento, mas uma forma de abordar temáticas ambientais desencadeando atividades em diversas disciplinas. Na Matemática, estabelecemos relações com a contagem de tempo, com o comportamento das pessoas em função da tecnologia, com a obesidade e o índice de massa corporal.

Na etapa seguinte, voltamos a falar sobre a tabela como forma de sintetizar as informações obtidas e de transmitir de forma clara e objetiva os dados pesquisados. Escolhemos o questionário como instrumento para a coleta de informações que posteriormente foram tabuladas e registradas em uma tabela que foi socializada. Esse questionário foi aplicado com a comunidade escolar, e versava sobre: o destino dado ao lixo em suas residências, o que acontece com o lixo produzido pela comunidade, os problemas causados pelo lixo, o lixo orgânico, a reciclagem, a coleta seletiva, poluição e a compostagem. Nesse sentido, a busca pelas informações ultrapassou o espaço escolar e invadiu o espaço familiar, o que trouxe a realidade para dentro da sala de aula.

Nesta transposição didática o trabalho desenvolvido foi para mais além do que a construção de tabelas. Esta atividade consistia na resolução e interpretação de problemas, cujo cálculo principal era o de porcentagem. A finalidade foi conduzi-los para reflexão, estabelecendo relações ao criar os questionamentos, levando a discussão para procurar entender e justificar os resultados obtidos nessas investigações, entre os diversos assuntos.

Diante da exposição feita, percebemos que ao inserir conteúdos do currículo escolar na realidade dos alunos, proporcionamos a eles entender a Matemática aplicada ao seu cotidiano de forma contextualizada. Além disso, possibilitou o uso da Matemática no desenvolvimento da cidadania.

Por fim, na última etapa do projeto, trabalhamos sobre a prática da compostagem como atividade alternativa de preservação e finalizamos com a construção da pilha de compostagem na escola, com materiais desperdiçados (restos de comidas e folhas de árvores), sensibilizando a comunidade escolar em relação ao descarte sustentável dos resíduos e estimulando a sua manutenção para uso na horta escolar.

Para instigar o princípio investigativo dos estudantes, vários questionamentos foram feitos em relação à compostagem, como: sua importância e o que pode e o que não pode ser usado ao fazer um compostor. 
A participação dos alunos foi muito importante, pois durante o processo da construção da pilha de compostagem, eles foram separando e guardando os resíduos orgânicos necessários da sua própria casa para que no dia da prática tivessem tudo em mãos. Essa atividade prática propiciou a interação entre os alunos, melhorando seus relacionamentos, além da conscientização do reaproveitamento do lixo doméstico.

Essa transposição didática trabalhou com o cálculo da quantidade e proporção de resíduos, relação de resíduo e outro material utilizado (como exemplo, serragem e folha seca) e tempo de decomposição, contribuindo com a formação dos alunos como sujeitos reflexivos e críticos com relação ao meio ambiente.

Vivenciamos nesse projeto todos os eixos estruturantes dos PCN: "números e operações", "grandezas e medidas", "espaço e forma” e "tratamento da informação", contextualizando os conteúdos escolares e incentivando a prática da investigação científica, aliada ao desenvolvimento de uma consciência ecológica.

Assim, com o intuito de transcender o ambiente escolar, finalizamos o projeto com uma caminhada pelo bairro, com o slogan "cidade limpa não é a que se varre e sim, a que menos suja”, socializando os conhecimentos adquiridos no processo de aprendizagem como afirma Maria Paula Zurawski, professora do Instituto de Educação Superior Vera Cruz (Isevec), em São Paulo "O reconhecimento da comunidade é um estímulo para que o aluno se empenhe em produzir o seu melhor".

\section{Considerações}

As atividades desenvolvidas com os Projetos "Brasil em Foco" e "Ambientando" no Colégio Estadual Camilo de Jesus Lima, contribuíram de forma significativa no processo de construção do conhecimento dos estudantes. Sabemos que novas metodologias vão surgindo como forma de possibilitar uma melhora na qualidade de ensino, portanto o trabalho desenvolvido foi de grande importância, na medida em que, proporcionou tanto aos professores quanto aos alunos uma nova perspectiva de mudança, trazendo a Matemática como matéria que busca interagir, dentro de um contexto, os conteúdos trabalhados para preparar os alunos para a vida.

A partir dessas considerações, temos a certeza que o trabalho com projetos oportuniza o aprendizado mais significado e que a metodologia da resolução de problemas é fundamental para a Educação Matemática.

Assim, através dessas atividades, elaboradas e executadas, os professores perceberam que ao relacionar os conteúdos curriculares num contexto, o mesmo passa a ter significado 
para o aluno, o que torna a aula mais prazerosa e os alunos passam a ter mais motivação para aprender algo novo.

A avaliação se deu em todas as etapas através da observação do envolvimento nas atividades e constatação de mudanças percebidas nos alunos, que passaram a questionar mais, a expor suas ideias e a se relacionar melhor uns com os outros.

Ensinar é como uma grande construção e cada dia é um desafio. Assim, a experiência vivida foi bastante enriquecedora. Pouco se fez e muito se conquistou o que permitiu atingir as competências e habilidades propostas.

\section{Referências}

BRASIL/MEC. Secretaria de Educação Fundamental. Parâmetros Curriculares Nacionais: Matemática. Brasília: 1997.

FREIRE, Paulo. Pedagogia da Autonomia: Saberes Necessários à Prática Educativa. São Paulo: Paz e Terra, 1994.

LORENZATO, Sérgio. Por que não ensinar Geometria? Educação Matemática em Relato de Experiência Revista, SBEM, 1995.

NACARATO, Adair Mendes; PASSOS, Cármen Lucia Brancaglion. A geometria nas séries iniciais: uma análise sob a perspectiva da prática pedagógica e da formação de professores. São Carlos: EDUFSCAR, 2003.

PAVANELLO, Regina Maria. Geometria: Atuação de professores e aprendizagem nas séries iniciais. In: Anais do I Simpósio Brasileiro de Psicologia da Educação Matemática. Curitiba: 2001.

PERRENOUD, P. Práticas pedagógicas, profissão docente e formação: perspectivas sociológicas. Lisboa: Dom Quixote, 1993.

TOMAZETTI, E. Estrutura conceitual para uma abordagem do significado da interdisciplinaridade: um estudo crítico. UFSM, n. 10, p. 1-43, 1998.

ZABALA, Antoni. A prática educativa. Tradução: Ernani F. da F. Rosa. Porto Alegre: ArtMed, 1998. 


\section{Bibliografia Resumida}

Adriana Cruz de Souza - Graduação em Licenciatura em Ciências com Habilitação em Matemática pela Universidade Estadual do Sudoeste da Bahia (UESB). Especialização em Curso de Pósgraduação Latu Sensu em Matemática pela Universidade Estadual do Sudoeste da Bahia (UESB). Professora titular do Colégio Modelo Luís Eduardo Magalhães.

Currículo Lattes: http://lattes.cnpq.br/5406455858804495

Contato: adrianacsouza25@gmail.com 